\title{
Why do Asian-American women have lower rates of breast conserving surgery: results of a survey regarding physician perceptions
}

\author{
Jane T Pham ${ }^{1}$, Laura J Allen ${ }^{1}$ and Scarlett L Gomez*1,2
}

Address: ${ }^{1}$ Northern California Cancer Center, Fremont, California (JTP, LJA, SLG), USA and ${ }^{2}$ Division of Epidemiology, Department of Health Research and Policy, Stanford University School of Medicine, Stanford, California (SLG), USA

Email: Jane T Pham - janethuypham@yahoo.com; Laura J Allen - lallen@nccc.org; Scarlett L Gomez* - scarlett@nccc.org

* Corresponding author

Published: 17 July 2009

BMC Public Health 2009, 9:246 doi:10.1 186/147/-2458-9-246
Received: 18 December 2008

Accepted: 17 July 2009

This article is available from: http://www.biomedcentral.com/I47I-2458/9/246

(C) 2009 Pham et al; licensee BioMed Central Ltd.

This is an Open Access article distributed under the terms of the Creative Commons Attribution License (http://creativecommons.org/licenses/by/2.0), which permits unrestricted use, distribution, and reproduction in any medium, provided the original work is properly cited.

\begin{abstract}
Background: US Asian women with early-stage breast cancer are more likely to receive a modified radical mastectomy (MRM) than White women, contrary to clinical recommendations regarding breast conserving treatment (BCT).

Methods: We surveyed physicians regarding treatment decision-making for early-stage breast cancer, particularly as it applies to Asian patients. Physicians were identified through the population-based Greater Bay Area Cancer Registry. Eighty (of 147) physicians completed a questionnaire on sociodemographics, professional training, clinical practices, and perspectives on the treatment decision-making processes.

Results: The most important factors identified by physicians in the BCT/MRM decision were clinical in nature, including presence of multifocal disease $(86 \%$ identified this as being an important factor for selecting MRM), tumor size (7I\% for MRM, 78\% for BCT), cosmetic result ( $74 \%$ for BCT), and breast size (50\% for MRM, 55\% for BCT). The most important reasons cited for the Asian treatment patterns were patient attitudes toward not needing to preserve the breast (53\%), smaller breast sizes (25\%), and fear and cultural beliefs (12\%).

Conclusion: These survey results suggest that physicians perceive major roles of both clinical and cultural factors in the BCT/MRM decision, but cultural factors may be more relevant in explaining surgical treatment patterns among Asians.
\end{abstract}

\section{Background}

For most patients with early-stage breast cancer, breast conserving treatment (BCT) provides a less invasive alternative to modified radical mastectomy (MRM) with equivalent survival [1] and possibly also better quality of life $[2,3]$. The use of BCT, however, occurs disproportionately in the US, with substantial ethnic, geographic and socioeconomic variation [4-8]. Asian women have MRM at significantly higher rates [5,7,9-11]; for example, in California, among stage 0-II breast cancer patients diagnosed in 1988-1995, 67.5\% of Asians had MRM compared to $57.3 \%$ of Whites [5]. This proportion is even higher among certain Asian populations; more current data from the national Surveillance, Epidemiology, and 
End Results (SEER) program show that 54\% of Vietnamese, $53 \%$ of Filipinas, and $48 \%$ of Chinese diagnosed with early-stage breast cancer between 1988-2005 had MRM, compared to $39-42 \%$ of non-Hispanic Whites, Blacks, and Hispanics $[9,12]$. BCT, which typically requires an average of five weeks of adjuvant radiation, may be less feasible for those who live far from treatment facilities and/or have travel limitations $[13,17]$. There are also clinical contraindications to BCT, such as small breast size, and a high tumor to breast size ratio [1], although it is unclear whether these clinical contraindications would explain the substantially lower rates of BCT among certain Asian populations. Other factors such as poor patient-provider communication, language barriers, and cultural factors may also affect the patterns seen in cancer surveillance data, yet patient sociodemographic or tumor characteristics have not been shown to explain the differences in treatment patterns across ethnic groups $[7,11,18]$. Qualitative research suggests that Asian cultural characteristics and beliefs about physical appearance, fate, and the safety and effectiveness of BCT, as well as difficulties with adjuvant treatment and cross-cultural misunderstandings in the doctor-patient encounter, may explain the higher frequency of MRM over BCT [10,19].

Physician perspectives can provide valuable insight into the decision-making process, and consequently, may help to identify reasons for racial/ethnic variations in treatment patterns. Factors such as provider gender [20], period of provider training [21], extent of communication between physician and patient [20], and hospital of diagnosis or distance to hospital or treatment facility [22] appeared to be associated with differences in choice of MRM between Black and White patients. The literature also documents limited concordance between patients' preferred role, with regards to autonomy and participation, and physician perception of this role in the decisionmaking process for breast cancer treatment [23], and for cancer treatment in general [24].

Because of the documented importance of physicians' perspectives in decisions regarding cancer treatment, and for understanding the persistently higher rates of MRM among Asian populations, we surveyed physicians from the Greater San Francisco Bay Area on their perspectives regarding the factors important in deciding between BCT and MRM. This survey is part of a larger pilot study of decision-making processes as they relate to ethnic disparities in receipt of optimal breast cancer treatment. This pilot study also included focus groups with breast cancer patients, and qualitative one-on-one interviews with patients and a "co-decision maker," and was designed to be a mixed methods study that incorporated all of the information gathered from the patient, co-decision maker, and provider interviews into a quantitative instrument, which was subsequently cognitive and pilot tested.

\section{Methods \\ Selection of Physicians}

Physicians were identified through the nine-county, population-based Greater Bay Area Cancer Registry (GBACR), a participant in SEER and in the California Cancer Registry (CCR). The GABCR covers a region of approximately 3 million residents and a racially/ethnically, socioeconomically, and geographically diverse population [25]. The names of the attending and follow-up physician of each breast cancer case, as well as their mailing address, are available from GBACR data. Other data, including physician sociodemographics and clinical specialty, are not available. Based on GBACR data for approximately 700 Chinese, 500 Filipina, and 120 Vietnamese incident breast cancer patients diagnosed during the years 20022004, we generated an eligibility sample of 50 physicians who had diagnosed and/or treated proportionally the most patients in each of these three racial/ethnic groups, for a total eligibility sample of 150 physicians.

\section{Survey Instrument}

The pre-tested, self-administered, mailed questionnaire consisted of 21 questions on physician socio-demographics, professional training and specialty, reported practices and guidelines, and perspectives on the treatment decision-making processes and factors considered important in treatment decisions. We also inquired about the overall racial/ethnic composition of each physician's patients, the extent to which clinical practice guidelines (or equivalent) were employed, and the estimated proportion of earlystage breast cancer patients treated with MRM. Questions about treatment decision-making processes developed by Bruera et al. [24] and Degner et al. [26] were adapted for use in this study. We also elicited physicians' perspectives on reasons why they thought Asian patients diagnosed with early-stage breast cancer are more likely to have MRM over BCT compared to the general population.

\section{Data Collection}

Eligible physicians were mailed, in 2005, a packet that included a cover letter describing the study and inviting them to participate by completing the enclosed questionnaire; completed questionnaires were received in 20052006. As an incentive to return the survey, a money order for $\$ 15$ was included. Telephone calls were made to encourage participation. Of the 150 physicians, three were deemed ineligible, and 80 surveys were completed, yielding a response rate of $54 \%$. Since the physicians were identified through the cancer registry, information on sociodemographic or other characteristics such as specialty type were not available for assessing whether respondents were different from non-respondents.

\section{Statistical Analysis}

The primary outcomes of interest were information about physician practices and perspectives regarding treatment 
decision-making. We conducted descriptive analyses of the physicians' reported practices and perspectives (Tables 1 and 2). We also conducted exploratory multivariable logistic regression of the associations between selected physicians' practices and perspectives and physician demographic characteristics. Analyses were performed using the R statistical program [27].

\section{Results}

Table 3 shows the frequencies of physician demographic characteristics. A relatively large proportion of our respondents were male (66\%), ranged in age from 40 to 59 years $(65 \%)$, and self-identified as non-Hispanic Whites (63\%). Most of the physicians were US-born (73\%), over half spoke English only (59\%), but many have had to discuss treatment in a foreign language $(64 \%$, often through an interpreter). $18 \%$ percent of physicians received training in oncology during their residency, and $35 \%$ during their fellowship.

Physician practices and policies are reported in Table 3. Largely attributable to our selection criteria, $77 \%$ of physicians reported that "several" (20-90\%) to "most" (greater than $90 \%$ ) of the breast cancer patients they treated over the past two years were Asian. Only 4\% treated more than $90 \%$ of their stage I and II breast cancer patients with MRM. In general, the physician-reported proportions of patients receiving MRM appear to be slightly lower than those based on population-based cancer registry data. These differences may be due to several factors, including some recall bias on the part of the physicians, and the differences in their patient populations by race/ethnicity and other sociodemographic factors.

Physician perspectives on important factors in the treatment decision are shown in Table 2. Frequently reported factors include clinical factors (tumor size, multifocal disease), breast size, and patient's attitude toward preserving the breast. For patients treated with BCT, $87.5 \%$ of physicians considered patient's attitude toward preserving the breast to be the most important factor, and 74\% of physicians also considered cosmetic result to be important.

$53 \%$ of physicians believed Asian women are more likely to have MRM because of patient attitudes about breast preservation, and $25 \%$ believed that breast size also plays a strong role. Physicians also listed fear and/or cultural beliefs as "other factors" influencing MRM decisions among Asian women.

Table I: Distribution of patient characteristics, practices, and guidelines, as reported by physicians $(\mathbf{N}=\mathbf{8 0})$, Greater San Francisco Bay Area, 2005-2006

\begin{tabular}{|c|c|c|c|c|c|}
\hline \multirow[t]{2}{*}{ Characteristics, practices, guidelines } & \multirow[t]{2}{*}{$N$} & None & A Few $(<20 \%)$ & \multirow{2}{*}{$\begin{array}{c}\text { Several } \\
\% *\end{array}$} & \multirow{2}{*}{$\begin{array}{c}\text { Most (>90\%) } \\
\% *\end{array}$} \\
\hline & & $\% *$ & $\% *$ & & \\
\hline \multicolumn{6}{|l|}{ Race/Ethnicity of patients treated over last 2 years } \\
\hline Non-Hispanic White & 75 & 1.3 & 9.3 & 60.0 & 29.3 \\
\hline Hispanic & 76 & 6.6 & 31.6 & 60.5 & 1.3 \\
\hline African American/Black & 77 & 9.1 & 52.0 & 39.0 & 0.0 \\
\hline Asian/Pacific Islander & 78 & 1.3 & 21.8 & 65.4 & 11.5 \\
\hline \multicolumn{6}{|l|}{ Patient decision-making preferences for treatment } \\
\hline Patient alone & 76 & 18.4 & 51.3 & I7.I & 13.2 \\
\hline Patient with physician input & 78 & 0.0 & 10.3 & 39.7 & 50.0 \\
\hline Shared decision & 78 & 0.0 & 15.4 & 38.5 & 46.2 \\
\hline Physician with patient input & 76 & 13.2 & 60.5 & 21.0 & 5.3 \\
\hline Physician alone & 77 & 45.4 & 42.9 & 11.7 & 0.0 \\
\hline \multirow[t]{2}{*}{ Hospital has facility-specific clinical practice guidelines (CPG) for patients } & & \multicolumn{2}{|r|}{ Yes } & \multicolumn{2}{|r|}{ No } \\
\hline & 80 & \multicolumn{2}{|r|}{27.5} & \multicolumn{2}{|r|}{72.5} \\
\hline $\begin{array}{l}\text { Number of patients for whom physicians employ these CPG } \\
\text { (among practices with CPGs, } N=23 \text { ) }\end{array}$ & 23 & 0.0 & 8.7 & 4.4 & 87.0 \\
\hline Number of stage I and II breast cancer patients treated with MRM & 74 & 1.4 & 68.9 & 25.7 & 4.0 \\
\hline
\end{tabular}

*Missing responses not included in percent calculations. 
Table 2: Physician perspective on factors determining treatment decisions (N = 80), Greater San Francisco Bay Area, $2005-2006$

\begin{tabular}{|c|c|}
\hline Physician perspective & \% indicating "yes" * \\
\hline \multicolumn{2}{|l|}{ Most important factors for stage I and II patients treated with MRM over last 2 years } \\
\hline Presence of multifocal or multicentric disease & 86.2 \\
\hline Tumor size & 71.2 \\
\hline Patient's attitude toward preserving the breast & 66.2 \\
\hline Breast size & 50.0 \\
\hline Age & 28.8 \\
\hline Location of tumor & 25.0 \\
\hline Patient's ability/willingness to travel to receive adjuvant radiation therapy & 22.5 \\
\hline Family history & 18.8 \\
\hline Cosmetic result & 17.5 \\
\hline Adverse effects/outcome & 6.2 \\
\hline \multicolumn{2}{|l|}{ Most important factors for stage I and II patients treated with BCT over last 2 years } \\
\hline Patient's attitude toward preserving the breast & 87.5 \\
\hline Tumor size & 77.5 \\
\hline Cosmetic result & 73.8 \\
\hline Breast size & 55.0 \\
\hline Patient's ability/willingness to travel to receive adjuvant radiation therapy & 38.8 \\
\hline Presence of multifocal or multicentric disease & 32.5 \\
\hline Age & 30.0 \\
\hline Location of tumor & 22.5 \\
\hline Adverse effects/outcome & 7.5 \\
\hline Family history & 6.2 \\
\hline \multicolumn{2}{|l|}{ Reasons why Asian subgroups are more likely to get MRM over BCT } \\
\hline Patient's attitude toward preserving the breast & 52.5 \\
\hline Breast size & 25.0 \\
\hline Age & 11.2 \\
\hline Patient's ability/willingness to travel to receive adjuvant radiation therapy & 10.0 \\
\hline Tumor size & 8.8 \\
\hline Adverse effects/outcome & 8.8 \\
\hline Cosmetic result & 7.5 \\
\hline Presence of multifocal or multicentric disease & 6.2 \\
\hline Location of tumor & 5.0 \\
\hline Family history & 2.5 \\
\hline Don't know & 17.5 \\
\hline Other & 18.8 \\
\hline Cultural factors & 6.2 \\
\hline Fear & 6.2 \\
\hline
\end{tabular}

*Non-response was counted as "No" for that factor.

We assessed associations between physicians' practices and perspectives and physician demographic characteristics using logistic regression (data not shown). Although based on a small sample, we found that Asians were less likely than physicians of other ethnicities to report cosmetic result as an important factor for patients choosing BCT $(\mathrm{OR}=0.13,95 \% \mathrm{CI}=0.04-0.40)$; male physicians were more likely than females to think cosmetic result was important in BCT decisions $(\mathrm{OR}=5.22,95 \% \mathrm{CI}=1.76-$ 15.49), and less likely to perceive that patient travel concerns were important $(\mathrm{OR}=0.21,95 \% \mathrm{CI}=0.08-0.58)$. When attempting to explain Asian treatment patterns, Asian physicians were more likely to perceive that patient age $(\mathrm{OR}=5.00,95 \% \mathrm{CI}=1.10-22.63)$ and travel concerns $(\mathrm{OR}=7.65,95 \% \mathrm{CI}=1.38-42.56)$ were important fac- tors. The full logistic regression results are available upon request.

\section{Discussion}

Breast cancer is the most commonly diagnosed cancer among Asian women [28-30], with the majority of cancers diagnosed at an early-stage. Because BCT is a recommended alternative to MRM, the fact that the vast majority of Asian women still have MRM is a concern, particularly if this treatment pattern reflects disparities in the delivery of guideline-recommended treatment. We found that physicians believed that patient attitudes toward [not] preserving the breast was the predominant reason for the higher rate of MRM among Asian women compared to other racial/ethnic groups. This finding supports sugges- 
Table 3: Distribution of physician demographic characteristics (N = 80), Greater San Francisco Bay Area, 2005-2006

\begin{tabular}{|c|c|c|}
\hline Characteristic & $n$ & $\% *$ \\
\hline \multicolumn{3}{|l|}{ Gender } \\
\hline Male & 53 & 66.2 \\
\hline Female & 27 & 33.8 \\
\hline \multicolumn{3}{|l|}{ Age (years) } \\
\hline Under 40 & II & 13.8 \\
\hline $40-49$ & 22 & 27.5 \\
\hline $50-59$ & 30 & 37.5 \\
\hline 60 and over & 17 & 21.2 \\
\hline \multicolumn{3}{|l|}{ Race/Ethnicity } \\
\hline Asian & 26 & 32.5 \\
\hline Non-Asian & 54 & 67.5 \\
\hline \multicolumn{3}{|l|}{ Country of Origin } \\
\hline USA & 58 & 72.5 \\
\hline Not USA & 22 & 27.5 \\
\hline \multicolumn{3}{|l|}{ Age Immigrated to US } \\
\hline US Born & 58 & 72.5 \\
\hline$<18$ yrs old & 10 & 12.5 \\
\hline $18+$ yrs old & 12 & 15.0 \\
\hline \multicolumn{3}{|l|}{ Foreign Language Fluency } \\
\hline English only & 47 & 58.8 \\
\hline Speaks more than English & 33 & 41.2 \\
\hline \multicolumn{3}{|c|}{ Discussed treatment in foreign language } \\
\hline Yes & 51 & 63.8 \\
\hline No & 23 & 28.8 \\
\hline \multicolumn{3}{|l|}{ Residency specialty } \\
\hline Medicine/Family & 17 & 21.2 \\
\hline General Surgery & 48 & 60.0 \\
\hline Radiation Oncology & 14 & 17.5 \\
\hline \multicolumn{3}{|l|}{ Fellowship specialty } \\
\hline Breast or Oncology & 28 & 35.0 \\
\hline Other specialty & 13 & 16.2 \\
\hline None & 39 & 48.8 \\
\hline
\end{tabular}

*Missing responses not included in percent calculations.

tions from qualitative studies that a primary reason for the observed surgical treatment pattern among Asians is reduced emphasis on physical appearance when making treatment decisions, reflective of cultural norms that place less significance on the breasts in particular $[10,19]$. This physician survey was conducted as part of a larger pilot study to evaluate such cultural factors and the role that they play in the complex decision-making process among Asian women diagnosed with early-stage breast cancer.

The second most commonly cited reason for the Asian surgical treatment pattern was breast size, given that BCT is often not clinically feasible considering the relatively small breasts among Asian women [1]. Our study did not show tumor size to be considered an important reason, which is consistent with prior studies that either have not shown a difference in tumor size distribution between Asian and non-Asian women $[7,18]$ or modest differences that were insufficient to explain the ethnic treatment differences $[8,9]$. These findings together suggest that MRM is more often performed on Asian women possibly because of contraindications in large tumor-to-breast ratios, which is primarily driven by small breast size, rather than large tumor sizes; however, tumor-to-breast ratio alone seems unlikely to explain all of the ethnic treatment differences. Because our findings consist of physician beliefs, further studies based on objective measures are needed to verify this finding.

The role of patient-provider cultural concordance may be relevant when examining Asian physicians' perspectives on decision-making process and treatment factors. Do Asian physicians draw from their own cultural experiences when interacting with Asian patients and when recalling patient treatment decisions? For example, difficulty in travel to receive adjuvant therapy (required as part of the full course of BCT) has been often considered as a reason for receipt of MRM over BCT [13-17], and proposed as a reason for the Asian treatment pattern [7]. Although few doctors in our study believed that this would explain why Asian patients are less likely to choose BCT, six of the eight doctors in our study that did perceive travel concerns to be a reason for the Asian treatment difference were of Asian race/ethnicity. Asian physicians were also much more likely to report that patient age may explain why Asian patients are more likely to choose MRM. It is difficult to determine whether this suggests that they believe that Asian breast cancer patients have a different age distribution from non-Asian patients, or whether they believe that Asian patients strongly link age to other treatment-relevant factors such as cosmetic result, attitude toward preserving the breast, and ability to travel. Asian physicians were also more likely to report that patients prefer that the physician makes the decision alone, suggesting cultural concordance as well as an implicit acknowledgement of the cultural belief in deference over medical professionals. Cultural concordance may play positive roles in patient care, as it has been associated with greater satisfaction with care [31], use of needed health services and less delay in seeking care, although these associations have been shown to be stronger for Whites and Blacks and less marked for Hispanics and Asians [32]. However, race concordance may result in poorer care; for example, it has been observed that physician sympathy for patient beliefs regarding cultural modesty and lack of emphasis on the importance of preventive care was associated with fewer recommendations for breast and cervical cancer screening [33].

The design aspect of this survey was limited in its ability to explore other factors in the decision-making process and possible explanations for Asian treatment patterns. For example, the study did not match providers to patients and did not attempt to examine concordance between patient and physician responses. Additionally, 
because physicians were selected based on the proportion of Chinese, Vietnamese, or Filipina patients treated, and given the heterogeneity among Asian subgroups, these results may not be applicable to patients of other Asian ethnicities.

Although this physician survey was conducted as part of a larger pilot study and was designed to be exploratory in nature, we were able to show that, from physicians' perspectives, while the main factors in deciding between BCT and MRM are clinical in nature, major reasons for the observed differences in surgical treatment patterns among Asian women are also believed to be psychological and cultural in nature. A main reason cited for electing BCT in general, and for the Asian treatment pattern is attitude toward preserving the breast. Although many of these cultural factors require additional research for a more complete understanding of their role and significance, physician awareness of these factors will allow them to incorporate this knowledge into their interactions with Asian breast cancer patients. In cases where there are no clear clinical contraindications to BCT, physicians should directly address the patient's attitude toward preserving the breast as well as other cultural factors. When a patient expresses that preserving the breast is not important, are they actually masking a fear of adverse outcomes or adjuvant therapy? Providers should be sure that patients are fully informed of their treatment options and of the consequences of each option. Finally, if travel is a barrier, as suggested through other studies of the general population [13-17], it should be possible to remove this barrier, either by providing private travel services or through coordination with existing public health or community programs. Through deeper understanding of the treatment decision-making process among Asian women is needed, early efforts such as these could contribute to reducing the racial/ethnic disparities in receipt of optimal breast cancer treatment.

\section{Conclusion}

In conclusion, this study of providers who have treated early-stage Asian breast cancer patients in the Greater San Francisco Bay Area showed that physicians perceive major roles of both clinical and cultural factors in the breast conserving therapy versus modified radical mastectomy decision, but psychological and cultural factors may be more relevant in explaining the previously documented higher MRM patterns among Asians.

\section{Authors' contributions}

All of the authors designed and implemented the study, and contributed to the writing of the manuscript. JTP took the lead in conducting the analysis and writing the manuscript. All authors have read and approved the final manuscript.

\section{Acknowledgements}

This research was supported by a grant through the National Cancer Institute (R2I CA 10920I). The collection of data used in this study was supported by the California Department of Health Services as part of the statewide cancer-reporting program mandated by California Health and Safety Code, Section 103885; by the National Cancer Institute 's Surveillance, Epidemiology, and End Results Program under contract NOI-PC35136 awarded to the Northern California Cancer Center and under contract N02-PC-15105 awarded to the Public Health Institute; and by the Centers for Disease Control and Prevention's National Program of Cancer Registries under agreement U55/CCR921930-02 awarded to the Public Health Institute. The ideas and opinions expressed herein are those of the author(s), and endorsement by the State of California, Department of Health Services, the National Cancer Institute, and the Centers for Disease Control and Prevention or their contractors and subcontractors is not intended nor should be inferred. We thank Christina Clarke Dur, Sarah Aroner, Sarah Shema, Cammie d'Entremont, Ashley Dunham, and Bang Nguyen for their contributions to this study.

\section{References}

I. NIH Consensus Conference: Treatment of early-stage breast cancer. JAMA I99I, 265(3):39I-5.

2. Ganz PA, Kwan L, Stanton AL, et al.: Quality of life at the end of primary treatment of breast cancer: first results from the moving beyond cancer randomized trial. J Natl Cancer Inst 2004, 96(5):376-87.

3. Nissen MJ, Swenson KK, Ritz LJ, Farrell JB, Sladek ML, Lally RM: Quality of life after breast carcinoma surgery: a comparison of three surgical procedures. Cancer 200I, 9 I (7): I238-46.

4. Joslyn SA: Racial differences in treatment and survival from early-stage breast carcinoma. Cancer 2002, 95(8): 1759-66.

5. Morris CR, Cohen R, Schlag R, Wright WE: Increasing trends in the use of breast-conserving surgery in California. Am J Public Health 2000, 90(2):28I-4.

6. Nattinger AB, Gottlieb MS, Veum J, Yahnke D, Goodwin JS: Geographic variation in the use of breast-conserving treatment for breast cancer. N Engl I Med 1992, 326(I 7): I 1 02-7.

7. Prehn AW, Topol B, Stewart S, Glaser SL, O'Connor L, West DW: Differences in treatment patterns for localized breast carcinoma among Asian/Pacific islander women. Cancer 2002, 95(I I):2268-75.

8. Goel MS, Burns RB, Phillips RS, Davis RB, Ngo-Metzger Q, McCarthy EP: Trends in breast conserving surgery among Asian Americans and Pacific Islanders, 1992-2000. J Gen Intern Med 2005, 20(7):604-II.

9. Gelber RP, McCarthy EP, Davis JW, Seto TB: Ethnic disparities in breast cancer management among Asian Americans and Pacific Islanders. Ann Surg Oncol 2006, I 3(7):977-84.

10. Killoran M, Moyer A: Surgical treatment preferences in Chinese-American women with early-stage breast cancer. Psychooncology 2006, I5(I I):969-84.

11. Lin SS, Phan JC, Lin AY: Breast cancer characteristics of Vietnamese women in the Greater San Francisco Bay Area. West J Med 2002, | 76(2):87-9|.

12. SEER*Stat Database: Incidence - SEER 9 Registries Limited-Use Database, November 2006 Submission (1973-2004). Surveillance Epidemiology and End Results Program, National Cancer Institute. Bethesda, MD . released April 2007

13. Athas WF, Adams-Cameron M, Hunt WC, Amir-Fazli A, Key CR: Travel distance to radiation therapy and receipt of radiotherapy following breast-conserving surgery. J Natl Cancer Inst 2000, 92(3):269-7I.

14. Celaya MO, Rees JR, Gibson JJ, Riddle BL, Greenberg ER: Travel distance and season of diagnosis affect treatment choices for women with early-stage breast cancer in a predominantly rural population (United States). Cancer Causes Control 2006, I7(6):85I-6.

15. Maskarinec G, Dhakal S, Yamashiro G, Issell BF: The use of breast conserving surgery: linking insurance claims with tumor registry data. BMC Cancer 2002, 2(1):3. 
16. Nattinger AB, Kneusel RT, Hoffmann RG, Gilligan MA: Relationship of distance from a radiotherapy facility and initial breast cancer treatment. J Natl Cancer Inst 200I, 93( I 7): I344-6.

17. Satariano ER, Swanson GM, Moll PP: Nonclinical factors associated with surgery received for treatment of early-stage breast cancer. Am J Public Health 1992, 82(2):195-8.

18. Gomez SL, France AM, Lee MM: Socioeconomic status, immigration/acculturation, and ethnic variations in breast conservingsurgery, San Francisco Bay area. Ethn Dis 2004, I4(I): $134-40$.

19. Kagawa-Singer M, Wellisch DK, Durvasula R: Impact of breast cancer on Asian American and Anglo American women. Cult Med Psychiatry 1997, 2 I (4):449-80.

20. Cyran EM, Crane LA, Palmer L: Physician sex and other factors associated with type of breast cancer surgery in older women. Arch Surg 200I, I36(2): 185-9|.

21. Jubelirer SJ, Harpold R, Miller S, Keener B, Slemp C: An analysis of factors determining the use of breast conserving surgery for treating early-stage breast cancer. W V Med J 200I, 97(3): $144-7$.

22. Satariano ER, Swanson GM, Moll PP: Nonclinical factors associated with surgery received for treatment of early-stage breast cancer. Am J Public Health I992, 82(2): 195-8.

23. Bruera E, Sweeney C, Calder K, Palmer L, Benisch-Tolley S: Patient preferences versus physician perceptions of treatment decisions in cancer care. J Clin Oncol 200 I, I 9( I I):2883-5.

24. Bruera E, Willey JS, Palmer JL, Rosales M: Treatment decisions for breast carcinoma: patient preferences and physician perceptions. Cancer 2002, 94(7):2076-80.

25. Cresswell SL GS, Clarke CA, Chang ET, Keegan THM, McClure LA, Rull RP, Shema SJ, West DW, Glaser SL: Cancer Incidence and Mortality in the Greater Bay Area. Annual Report - Northern California Cancer Center, Fremont, CA 2008.

26. Degner LF, Kristjanson LJ, Bowman D, et al: Information needs and decisional preferences in women with breast cancer. Jama 1997, 277(18): I 485-92.

27. Bates $D$, Chambers J, Dalgaard $P$, et al.: $\mathbf{R}$ Program [R]. version 2.8.0. The R Foundation for Statistical Computing.

28. Cockburn M, Deapen D, eds: Cancer Incidence and Mortality in California: Trends by Race/Ethnicity 1988-200I. Sacramento, CA: Department of Health Services; 2004.

29. Gomez SL, Le GM, Miller T, Undurraga DM, Shema SJ, Stroup A Clarke CA, Keegan THM, O'Malley CD, Unger Hu K, West DW, Glaser SL: Cancer Incidence among Asians in the Greater Bay Area, 1990-2002. Fremont, CA 2005.

30. Miller BA, Chu KC, Hankey BF, Ries LA: Cancer incidence and mortality patterns among specific Asian and Pacific Islander populations in the U. Cancer Causes Control 2008, 19(3):227-56.

31. Laveist TA, Nuru-Jeter A: Is doctor-patient race concordance associated with greater satisfaction with care? J Health Soc Behav 2002, 43(3):296-306.

32. LaVeist TA, Nuru-Jeter A, Jones KE: The association of doctorpatient race concordance with health services utilization. J Public Health Policy 2003, 24(3-4):3 I 2-23.

33. Lee MM, Lee F, Stewart S, McPhee S: Cancer screening practices among primary care physicians serving Chinese Americans in San Francisco. West J Med 1999, 170(3): 148-55.

\section{Pre-publication history}

The pre-publication history for this paper can be accessed here:

http://www.biomedcentral.com/1471-2458/9/246/pre pub
Publish with Bio Med Central and every scientist can read your work free of charge

"BioMed Central will be the most significant development for disseminating the results of biomedical research in our lifetime. "

Sir Paul Nurse, Cancer Research UK

Your research papers will be:

- available free of charge to the entire biomedical community

- peer reviewed and published immediately upon acceptance

- cited in PubMed and archived on PubMed Central

- yours - you keep the copyright
BioMedcentral 